\title{
Esprit de corps in Haiti
}

\section{Matthew J. Hornbach and colleagues navigated shallow debris-filled waters in an attempt to understand the factors that contributed to tsunami generation during the Haiti earthquake.}

How did you end up working in Haiti? On 7 January 2010, an unusual e-mail arrived in my office in Austin, Texas, from my colleague Paul Mann. Paul has studied Hispaniola geology for decades and was writing from the Dominican Republic where he was on vacation (apparently not a reason to stop working). The e-mail contained photos showing aseismic subsidence of the Hispaniola shore indicating that the coastline was sinking. Burnt into my memory is the caption he wrote for these photos: "Harbinger of impending earthquake?" Five days later the $M_{\mathrm{w}} 7.0$ earthquake struck. As chance would have it, I had recently started working on the Jamaican portion of the Enriquillo-Plantain Garden fault - a fault that continues from Jamaica into Haiti. So extending my research to Haiti was a natural fit. I jumped at the opportunity to join the Haiti study.

What was the objective of the work? Originally our objectives were basic because the geology around Hispaniola is poorly constrained. An initial goal was to determine the location and orientation of active faults so that we could better understand seismic hazards. As we acquired more data, we began to grasp the complexity of the geology across the region. We have only scratched the surface when it comes to understanding Haiti's geology, yet it is critical that we understand it. Complex fault systems like the one around Haiti are widespread and several cities including Kingston (Jamaica), Los Angeles (California) and Istanbul (Turkey) are situated in similar geologic environments and exposed to significant seismic hazards.

Did you encounter any difficulties? Conducting field work in a developing nation is often difficult, but even more so in the aftermath of a catastrophe. The earthquake caused significant disruption

to Haiti's government, making it difficult even to know who to contact for necessary permits to conduct our research. The team working on land struggled to get to sites because many roads were

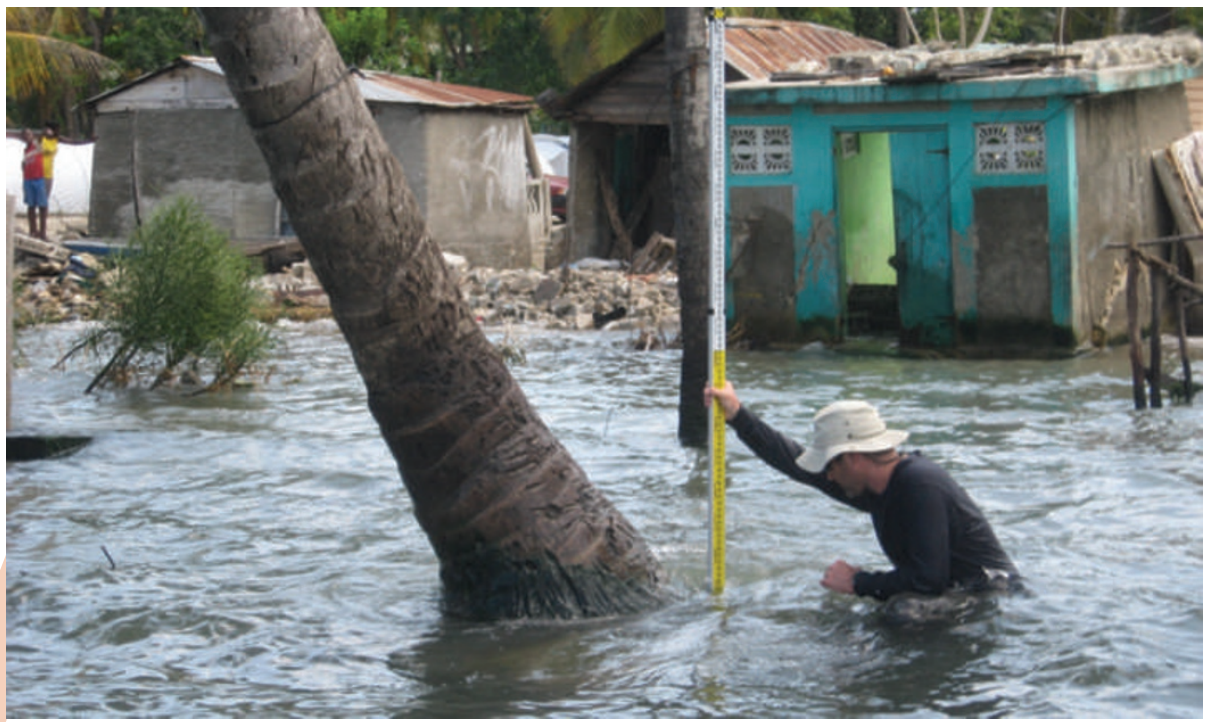

Rich Briggs struggles to collect measurements along a now sunken shoreline south of Petit Goâve, after it was hit by a tsunami resulting from the 2010 Haiti earthquake.

destroyed. Helicopters and boats often played a key role in transport. We carried out much of our field work by ship on the RV Endeavor, but there were also several marine hazards. Many residents would sleep or fish in their small boats at night. These boats are very difficult to identify on radar, and the crew of Endeavor were constantly on the lookout to avoid collisions. Marine charts were also out of date and, combined with coral uplift during the earthquake, data collection near the shore was a real challenge. The captain and crew of Endeavor did a fantastic job balancing our scientific objectives with the risk of running aground. The amount of debris cluttering the ocean following the earthquake represented yet another substantial hazard, and our instruments became entangled a few times. Looking back at all these complications and the short time (two weeks) to conduct this research, I'm amazed at how much we were actually able to accomplish.

\section{Any low points?}

When we first started collecting data in a small open boat right along the shoreline of Petit Goâve, we could see the devastation up close: it extended as far as the eye could see. There was no beginning or end, just destruction everywhere. Sitting in that boat I felt very small, but also very motivated.

\section{What was the highlight of the expedition?}

An amazing esprit de corps developed among researchers during the study. A committed, diverse team of world-class scientists and students from across the United States and Haiti worked night and day, shoulder-to-shoulder collecting, processing and interpreting these data. Our work was truly a team effort and I feel very lucky to be a member of this team.

Did the trip give you any ideas for future research projects?

We aim to better constrain the offshore tectonics and palaeoseismicity of the fault systems in Haiti. Furthermore, we have received funding from Geoscientists Without Borders, a project set up by the Society of Exploration Geophysicists to study the extension of the Enriquillo-Plantain Garden fault system near Kingston, Jamaica, and to assess future geohazards for this region.

This is the Backstory to the work by Matthew J. Hornbach and colleagues, published on page 783 of this issue. 